\title{
Study on Doctor-patient Relationship Laxation under the New Media Environment
}

He Zichen

\author{
Chongqing Normal University, Chongqing400000
}

\begin{abstract}
The contradictions between doctors and patients caused by medical disputes has become one of the hot topics in the society. The contradictions between doctors and patients not only is the conflict influencing the economic and spiritual interests of doctors and patients, but also is a social problem influencing social stability and solidarity and going against the establishment of harmonious society. The new media era with network as the core has been coming, and it is an irreversible phenomenon that the public get involved in public affairs and express their opinions by new media. How to alleviate the doctor-patient relationship under the perspective of new media is a new research focus. The paper mainly expounds the new situation and mitigation schemes of doctor-patient relationship under the background of new media。
\end{abstract}

Key words: new media age, doctor-patient disputes, alleviation scheme

\section{Introduction}

The new media technology develops rapidly, and the boundary between the communicators and the audiences has been blurred increasingly. And the emerging media makes traditional linear propagation become network interaction. Microblog, forum, blogs and podcast with internet as the carrier is becoming the important source of news. The concealment, rapidness and word chaos of multi-channel news release brings new challenges for governmental news release and defusing public crisis in gusty public events. With the increase of channels of the public participating in public events, the doctor-patient relationship which is a sensitive social problem is more complicated. How to alleviate the doctor-patient relationship under the environment of new media is very important.

\section{Evolution of Doctor-patient Relationship}

The basic principle of medical ethics of socialism is retrieving the dying or rescuing the wounded, preventing form and curing diseases, and it implements humanitarianism of socialism and serve for the health of the people with heart and soul. Compared with doctor-patient relationship in feudal society and capitalist society, the doctor-patient relationship under socialism has essential features. The doctors and patients are the host of the society, the relationship between them is equal, and there is no conflict of interests and employment relationship. The medical staff serve the society and patients, and the society and the restorative patients serve for the medical staff, which is interdependent and promotes each other. In the doctor-patient relationship, the medical staff are predominant, and plays the role of major decision. The position and function is conditional and variable. Modern medial pattern still has biological factors. No matter whatever technical methods or instruments are used, the medical staff still provide service for the patients, and the patients are the attendee, and the initiative enhances greatly. 
In the planned economy era in China, the doctor-patient relationship is very simple, and is only the relationship between serving and being served. The doctors and patients play different role, and there are fewer disputes because of economy under the system of free medical service. With the social progress and economic development, the doctor-patient relationship changes greatly. Firstly, the hospital transfers from planned economy to market economy. State-owned hospitals become the stakeholder with independent consciousness implementing independent economic accounting. Under the condition of deficient national financial investment, supporting hospital with the medicine is the second economic source to subsidy insufficient government investment for the survival of the hospitals. The medical market competition is fierce. In order to win the competition and develop rapidly, the hospitals improve hardware and the environment increasingly, which needs to be based on powerful economy. Meanwhile, the intervention of medical facility and pharmaceutical enterprises in medical market indirectly makes the medical expense increase. Once the rise exceeds the limitation of the patients, the distrust between patients and doctors increases. With the marketization of hospitals, the enhancement of commodity consciousness and right-protection awareness of the people, the doctor-patient relationship is transforming into contractual relation.

\section{Development Trend of Doctor-patient Disputes in China}

In recent years, doctor-patient disputes have become the problems which are difficult to be solved in some hospitals, and have severely influenced normal medical order and social stability in some hospitals. In fact, the doctor-patient disputes at home and abroad have increasing tendency, which not only is the necessary phenomenon in commodity society and the society ruled by the law, but also is the new characteristic in medical industry.

The development of doctor-patient disputes is from the process of medical system information. There is information asymmetry in various fields, but the information in medical field is too asymmetric, which indicates that it is insufficient in China. The reason why patients see a doctor is that they don't know what's wrong with their bodies, which needs to be solved by the doctor. The doctor needs to diagnose the patients, and tell the patients what medicine they should take and what examination they should make, which is called principal-agent relationship in economics. The patient is the principal, and the doctor is the agent of the patient, and the doctor makes decisions for the patients. If the people who makes decisions for you wants to make money, we can imagine what result it is. It is known that the consumer have option. But in medical field, the option of the consumer is an illusion. The patients only can choose if the attitude of the doctor is good, if the medical environment is good, if the instrument is advanced, and if the medicine is good, which can't represent the medical effect. Therefore, the patients have no option in fact. And the contradictions cause doctor-patient disputes.

\section{Response in Doctor-patient Relationship under the Environment of New Media}

\subsection{Hospital image recovery strategy}

Image recovery theory is appropriate after image crisis, and the essential is the words in the crisis. In the new media age, hospital image faces more challenges, and the factors influencing hospital image are more complicated. It is necessary to improve hospital image consciousness, establish public right-protection concept, improve information publication system, establish hospital responsibility mechanism and enhance administrative force, which not only can avoid hospital image crisis, but also can maintain and 
restore good hospital image. The important premises of image recovery strategy under new media context are as follows.

(1) The degree of the hospital organizations taking charge for an event or a behavior.

(2) If the opinions of the public for the responsibility is more important than knowing the truth of the event.

In conclusion, when the event takes place, if the public consider that the organization has responsibility, it is necessary to make image recovery, and the truth of the event is secondary. Bennett thought that the organization should actively undertake the obligations after crisis to reduce the image impairment degree to the minimal in the shortest time.

When the crisis takes place, communication is the most key, or is the core link to solve crisis. Formulating and selecting proper communication strategy is very important, and is the important step for any organization to successfully process the crisis. There are different reasons for public crisis of hospitals. It has great significance for crisis rhetoric direction research to use organization image restoration theory of Bennett to take appropriate communication strategies under different crisis stages for reducing the damage of crisis on hospital image to the minimal.

Under the premise of new media context, the researchers divide hospital image recovery strategies in public events into accidental situation image recovery strategy and fault situation image recovery strategy. The main representation of accidental situation crisis is natural disaster, and the main characteristics are force majeure of crisis causes, small organization responsibility and great external control force. From the perspective of the importance of information, the major image recovery strategy is support and correction. The major representation of fault situation crisis is gusty significant accident. The main characteristics are great responsibility of organizations and great personal control force. From the perspective of the importance of information, the main repair strategy is defense and self-accusation. Hospital crisis strategy transforms from denial, shift and clarification into correction behavior of exploring the truth of the accident, which fully indicates that the primary task of the hospitals dealing with crisis in the new media age. From the above researches, we can get the conclusion of the response strategies for the information release of hospitals, as follows.

(1) The emotion of humanized comfort for the victim and the family in information release.

(2) Timely exploring and giving the truth, and calming down the doubt and the angry of the public.

(3) Reflecting the sincerity and courage of the responsible party for accident management and accountability.

We can see that under new media context, the image recovery strategy of hospitals is not administrative procedure any longer. As rapid and effective monitoring tool, new media makes the investigation and disposal of crisis develop towards public and transparent. Once gusty public accidents take place, doubt, horror and opposition becomes the common psychology of the public. If the hospitals don't timely implement image recovery strategies, there must be some unstable factors. The factors are the same to the damage of the crisis, which makes the hospital image worse, makes the image recovery more complicated and difficult, and enhances the damage. Therefore, in the process of image maintenance and recovery, the hospitals must adapt to the characteristics of new media age, maintain good hospital image and establish firm new media position in crisis rhetoric.

\subsection{Hospital defense strategy}

Under the tendency that new media develops rapidly, there is the influence of network media everywhere. Public opinions have no rule to obey, and the hospitals have no principles in defense process, and the image is different in the heart of the media and the public, which makes the medium trail prevalent, 
and breaks the stable operation of social system.Therefore, there is necessary for hospitals organization to make correct definition on crisis at the first time, which not only can capitalize the trend, but also can achieve the objective of alleviating the crisis.

\section{Case Analysis}

(1) Doctor-patient wave caused by a micro-blog. In February 2014, Wang Mudi, a famous host in Guangdong satellite, accompanied his girlfriend to be injected with intravenous drip. The nurse found out the blood vessels after four injections. And he said that he wanted to chop up the people in the blog. In the evening, Wang Mudi deleted the blog and apologize in public. But the blog still causes great wave, which threw the doctor-patient relationship into the spotlight. The media mislead activated the doctor-patient relationship.

There are objective reasons for harmonious doctor-patient relationship. The reasons why the patients see a doctor are pain diseases, high cost and complicated procedures. For the patients, the repeated labor and psychological pressure is easy to make them out of sorts. The patients hope that the medical institutions can take measures. The essence is that there is no tolerance and belief between the patients and the doctors. The hospitals need to enhance the communication and improve service quality. Doctor-patient relationship needs to be established by the medical institutions, medical staff and patients. The medical institutions should adhere to the aim of serving people, and puts the interest of the mass first, establish perfect communication system and complaint system to reduce the contradictions and avoid extremalization. Under normal conditions, the bad attitude of medical staff is the propellant making the doctor-patient contradictions upgrade. The medical staff should understand the pain of the patients, respect the desire of the patients, and communicate and explain with the patients to make the patients fully know about the disease.

(2) A cozy micro-blog alleviates doctor-patient relationship

At the end of 2012, there was a blog that no matter wherever you are, you should go to the hospital nearby for treatment and cherish yourself. There was a patient who was difficult to be saved back left without saying goodbye. The First People's Hospital in Hangzhou worried about the disease of the patients rather than not paying for the medical fee, and published a special people lost in official micro-blog. The attending doctor enclosed a prescription and told him to take medicine timely.

The micro-blog moved many netizens. The mass praised the hospital and the attending doctor. Even some people said that they began to believe the doctor again.

Why did a micro-blog move so many people? Some netizens explained that doctor-patient relationship had become social pain, and the doctors have become white horror from white angel. However, the micro-blog reflects the essence of the hospitals and doctors with patients as the center.

Most doctors are responsible and reasonable. We should learn empathy. For example, the doctors should know that seeing a doctor is difficult and expensive, and the patients should understand the hard working of the doctors. A medical accident may make the public not believe in the doctors, and a micro-blog may reestablish the bridge of belief.

\section{Conclusions}

There are no technical reports about hospital in new media. As the media, technical words are dull. However, technical report can relieve the doctor-patient relationship, and improve the quality of the patients for medical health. The public have no interest in technical words, and the new media has misunderstanding. Technical news also can make new media easy to be accepted. No mater whatever 
contributions, the moving factors are necessary, which means that there is communication value. For example, technical contributions can use new, strange and special events as communication content, and can transform rigid technical contributions into story report. The report experience needs the communication of the new media and hospitals. How to effectively avoid the nervous doctor-patient relationship under the environment of new media includes,

(1) The government should enhance the investment in health service, optimize resource allocation, improve financial compensation mechanism and operation mechanism of hospitals, ensure subsidy expense, and nonprofit nature of hospitals. (2) The government should make the relative laws and regulations sound. In medical activities, practicing medicine of doctors and seeing a doctor of patients is protected and restricted by laws and regulations. The doctor-patient relationship should be brought into normalized. (3) The hospitals should enhance the internal management.

\section{References:}

[1] Jiang Shengyun, Ren Xueli, Moral principles about medical micro-blog [J], Chinese Medical Ethics, 2013,04:507-508.

[2] Chen Hua, Ye Chenyu, Liu Wenjuan, Zhang Hongxia, Ji Jianlin, Yang Zhen, Observation on communication of doctor-patient relationship in socialized media age $[\mathrm{J}]$, Medicine and Philosophy(A),2014,03:52-54.

[3] Huang Xinru, Media transformation can't lose social responsibility [J], Youth Journalist, 2014,25:48.

[4] Jiang Xuemei, Han Zhenwen, Experience of working in hospital office under new situation of doctor-patient relationship [J], Office Operation, 2014,19:11.

[5] Liu Guoqing, Observation and analysis on anomie phenomenon of doctor-patient relationship reported by media - - taking the death of the puerpera in Xiangtan as an example [J], Yong Journalist, 2014,35:7-8.

[6] Wu Nina, Making good official micro-blog to transfer positive energy of hospital [J], Jiangsu Healthcare Administration, 2014,06:65-66. 